\title{
Validation of tissue microarray technology in squamous cell carcinoma of the esophagus
}

\author{
Judith Boone $\cdot$ Richard van Hillegersberg • \\ Paul J. van Diest • G. Johan A. Offerhaus • \\ Inne H. M. Borel Rinkes • Fiebo J. W. Ten Kate
}

Received: 6 December 2007 /Revised: 30 January 2008 / Accepted: 25 February 2008 / Published online: 8 April 2008

(C) The Author(s) 2008

\begin{abstract}
Tissue microarray (TMA) technology has been developed to facilitate high-throughput immunohistochemical and in situ hybridization analysis of tissues by inserting small tissue biopsy cores into a single paraffin block. Several studies have revealed novel prognostic biomarkers in esophageal squamous cell carcinoma (ESCC) by means of TMA technology, although this technique has not yet been validated for these tumors. Because representativeness of the donor tissue cores may be a disadvantage compared to full sections, the aim of this study was to assess if TMA technology provides representative immunohistochemical results in ESCC. A TMA was constructed containing triplicate cores of 108 formalin-fixed, paraffin-embedded squamous cell carcinomas of the esophagus. The agreement in the differentiation grade and immunohistochemical staining scores of CK5/6, CK14, E-cadherin, Ki-67, and p53 between TMA cores and a subset of 64 randomly selected donor paraffin blocks was determined using kappa statistics. The concurrence between TMA cores and donor blocks was moderate for Ki-67 $(\kappa=0.42)$ and E-cadherin $(\kappa=0.47)$, substantial for differentiation grade $(\kappa=0.65)$ and CK14 $(\kappa=0.71)$, and almost perfect for p53 $(\kappa=0.86)$ and CK5/6 $(\kappa=0.93)$. TMA technology appears to be a valid method for immunohistochemical analysis of molecular
\end{abstract}

J. Boone $(\square) \cdot$ R. van Hillegersberg $\cdot$ I. H. M. Borel Rinkes Department of Surgery, University Medical Center Utrecht, G04.228, Heidelberglaan 100,

3584 CX Utrecht, The Netherlands

e-mail: jboone2@umcutrecht.nl

P. J. van Diest • G. J. A. Offerhaus · F. J. W. Ten Kate Department of Pathology, University Medical Center Utrecht, Heidelberglaan 100 ,

3584 CX Utrecht, The Netherlands markers in ESCC provided that the staining pattern in the tumor is homogeneous.

Keywords Biological markers · Esophageal neoplasms . Protein microarray analysis · Squamous cell carcinoma . Validation studies

\section{Introduction}

Esophageal carcinoma is the eighth most common type of cancer in the world [13]. Although the recent rise in incidence of esophageal cancer has predominantly been caused by an increase in adenocarcinomas, the majority of esophageal cancer cases globally are squamous cell carcinomas [13]. For both histological types, radical en bloc esophagectomy with an extensive lymph node dissection offers the best chance for cure, leading to an overall 5 -year survival rate of around $30 \%[1,20]$.

Well-known histopathological factors for prognostication of esophageal cancer include the TNM stage, the number of positive lymph nodes, and the presence of extracapsular lymph node involvement [16, 24, 26, 32]. Recently, there has been a growing interest in the prognostic value of molecular markers in (esophageal) cancer [21]. The expression of such markers is often studied by immunohistochemistry on formalin-fixed, paraffin-embedded tumor slides. Tissue microarray (TMA) technology has been developed to enable high-throughput immunohistochemical analyses [14]. By inserting small (diameter e.g. $0.6 \mathrm{~mm}$ ) donor tissue core biopsies into a single recipient paraffin block, this technique allows for rapid analysis of large numbers of tissues under standardized laboratory and evaluation conditions without significantly damaging the patient's tissue. In addition, TMA technology leads to a significant 
reduction of the amount of consumables used and time needed for interpretation, increasing cost-effectiveness.

A potential disadvantage compared to full tissue sections is that the donor cores may not be representative for the whole tumor, particularly in case of heterogeneous tumors and heterogeneously expressed molecular markers. Hence, some validation studies have been performed in various cancers using different kinds of antibodies $[2,4,6,7,9,12$, 23, 35]. Although several studies have revealed novel prognostic biomarkers in esophageal squamous cell cancer (ESCC) by means of TMA technology [38, 39, 41], this technique has not yet been validated for these tumors.

The aim of the present study was, therefore, to validate TMA technology in ESCC by assessing the concurrence of immunohistochemical staining scores of established molecular markers with various expression patterns between triplicate $0.6 \mathrm{~mm}$ core biopsies of the TMA and their whole tissue section counterparts.

\section{Materials and methods}

\section{TMA construction}

Formalin-fixed, paraffin-embedded tissues from thoracic ESCCs of consecutive patients having undergone esophagolymphadenectomy at the authors' institute between 1989 and 2006 were retrieved from the archives of the Department of Pathology. Patients who received neoadjuvant therapy were excluded from this study. The study was carried out in accordance with the ethical guidelines of our institution concerning informed consent about the use of patient's materials after surgical procedures.
By an experienced pathologist (FtK), three representative tumor regions were marked on one selected hematoxylin and eosin (H\&E)-stained section of each tumor, avoiding areas of necrosis. From these three tumor regions, a tissue cylinder with a diameter of $0.6 \mathrm{~mm}$ was punched out of the corresponding paraffin block ('donor block') and placed into the TMA paraffin block using a manual tissue arrayer (MTA-I, Beecher Instruments, Sun Prairie, USA), which was guided by the MTABooster ${ }^{\circledR}$ (Alphelys, Plaisir, France). The distribution and position of the cores was determined in advance with the TMA-designer Software (Alphelys-TMA Designer ${ }^{\circledR}$, Version 1.6.8, Plaisir, France). Cores of normal esophageal mucosa, lymph node, kidney, liver, spleen, and prostate were incorporated in the tissue array block as internal controls.

\section{Immunohistochemistry}

For each marker, a 4- $\mu \mathrm{m}$ slide of the TMA and one of every selected donor paraffin block were immunohistochemically stained. Table 1 shows the details of all antibodies, dilutions, incubation times and antigen retrieval methods applied in this study.

For all stainings, sections were deparaffinized in xylene for $10 \mathrm{~min}$ followed by dehydration through graded alcohols. Endogenous peroxidase activity was blocked for $15 \mathrm{~min}$ in a buffer solution of $\mathrm{pH} 5.8$ (containing $8.32 \mathrm{~g}$ citric acid, $21.52 \mathrm{~g}$ disodium hydrogen phosphate, $2 \mathrm{~g}$ sodium azide in 11 of water) with hydrogen peroxide $(0.3 \%)$. After antigen retrieval for $20 \mathrm{~min}$, a cooling down period of $30 \mathrm{~min}$ was followed by incubation with the primary antibody. Depending on the antibody used, slides were incubated with the secondary antibody followed by

Table 1 Specification of antibodies used and details of tissue processing

\begin{tabular}{|c|c|c|c|c|c|c|c|c|c|}
\hline $\begin{array}{l}\text { Primary } \\
\text { antibody }\end{array}$ & $\begin{array}{l}\text { Staining } \\
\text { pattern }\end{array}$ & Source ${ }^{a}$ & $\begin{array}{l}\text { Clone and } \\
\text { code }\end{array}$ & $\begin{array}{l}\text { Antigen } \\
\text { retrieval }\end{array}$ & Dilution & $\begin{array}{l}\text { Incubation } \\
\text { time (min/room } \\
\text { temperature) }\end{array}$ & Detection $^{\mathrm{b}}$ & Positive control & Procedure \\
\hline $\mathrm{CK} 5 / 6$ & Cytoplasmic & Chemicon & D5/16 B4 & EDTA pH 9.0 & $1: 3,000$ & 60 & Strept ABC & Breast & Autostainer \\
\hline CK14 & Cytoplasmic & Neomarkers & LL002 & EDTA pH 9.0 & $1: 400$ & 60 & Powervision & Breast & Autostainer \\
\hline E-cadherin & Membranous & Zymed & $4 \mathrm{~A} 2 \mathrm{C} 7$ & $\begin{array}{l}\text { Citrate autoclave } \\
\mathrm{pH} 6.0\end{array}$ & $1: 200$ & 60 & Powervision & Breast & Autostainer \\
\hline $\begin{array}{l}\text { MIB-1 } \\
\quad(\mathrm{Ki}-67)\end{array}$ & Nuclear & Dako & M7240 & Citrate $\mathrm{pH} 6.0$ & $1: 100$ & 60 & Strept ABC & Tonsil & Autostainer \\
\hline p53 & Nuclear & Biogenex & BP53-12 & Citrate $\mathrm{pH} 6.0$ & $1: 200$ & 60 & Strept ABC & $\begin{array}{l}\text { Serous } \\
\text { adenocarcinoma } \\
\text { of the } \\
\text { endometrium }\end{array}$ & Autostainer \\
\hline
\end{tabular}

\footnotetext{
${ }^{a}$ Biogenex, San Ramon, CA, USA; Chemicon, Chemicon International, Temecula, CA, USA; Dako, DakoCytomation, Glostrup, Denmark; Neomarkers, Fremont, USA; Zymed, Zymed Laboratories, San Francisco, CA, USA.

${ }^{\mathrm{b}}$ Strept ABC is biotinylated horse-antimouse Vector BA-2000, diluted 1:500 in PBS, followed by streptavidin-biotin complex, diluted 1:1,000. Powervision ready to use (Poly-HRP-antiMs/Rb/RtIgG biotin-free; ImmunoVision Technologies, Norwell, CA, USA).
} 
the streptavidin-biotin complex or slides were directly incubated with Powervision (details of both products shown in the legend of Table 1). Then, the peroxidase reactivity was developed by 3,3'-diaminobenzidine for $10 \mathrm{~min}$ and slides were counterstained with Mayer's hematoxylin. In between steps, slides were washed with phosphate-buffered saline (pH 7.4).

Immunohistochemical scoring

By two observers (FtK and JB) conjointly, the degree of differentiation and the percentage of immunohistochemically stained tumor cells were determined in all TMA cores and in the full sections of the selected donor blocks. Histologic grade was scored as well-differentiated (G1), moderately differentiated (G2), or poorly differentiated (G3) [37]. Staining of p53 and Ki-67 were marked as negative $(<10 \%$ of tumor nuclei stained), weakly positive $(10-50 \%)$, or strongly positive $(\geq 50 \%)[10,40]$. Cytokeratin (CK)5/6 and CK14 staining were scored as negative $(<10 \%$ of tumor cell cytoplasms stained), weakly positive $(10-80 \%)$, or strongly positive $(\geq 80 \%)$. E-cadherin expression was regarded negative when $<50 \%$ of tumor cell membranes stained and positive when $\geq 50 \%$ stained $[29,30]$.

Cores were considered lost if $<10 \%$ of cells contained tumor ('sampling error') or when $<10 \%$ of tissue was present ('absent core'). Cases were excluded if two out of three cores were lost. When the scores between the cores of a particular case differed, the most frequent score determined the overall score. In case of three different scores in one case, the middle score was chosen. When only two cores were available with both a different score, the case was excluded from further analysis [11].
Statistical analysis

Statistical analyses were performed using the SPSS software for Windows (Version 12.0, SPSS, Chicago, IL, USA). Sixty-four donor blocks $(60 \%$ of the tumors incorporated in the TMA) were randomly chosen by means of a random selection function of SPSS.

To determine the chance-corrected agreement between the immunohistochemical staining scores of TMA cores and large sections, the Cohen's weighted kappa statistic was calculated. Chance-corrected agreement was considered poor if $\kappa<0.00$, slight if $0<\kappa<0.20$, fair if $0.21<\kappa<0.40$, moderate if $0.41<\kappa<0.60$, substantial if $0.61<\kappa<0.80$, and almost perfect if $0.81<\kappa<1.00$ [17]. The overall agreement was defined as the percentage of correct agreement between the TMA and the donor blocks from the total number of cases [15].

\section{Results}

Of the $324(3 \times 108)$ tumor tissue cores that were transferred into the TMA paraffin block, a median of 295 (91\%) was available for immunohistochemical scoring on the 6 TMA slides used in this study (Table 2). Of the 64 randomly selected cases, a median of $176(92 \%)$ of 192 cores $(3 \times 64)$ was evaluable on the TMA slides.

On the H\&E-stained TMA slide, 49 (76\%) of the 64 randomly chosen cases were represented by 3 cores; 14 $(22 \%)$ by 2 cores. One (1.6\%) case was excluded from further analysis because only a single core was available. The agreement in the scores for the grade of differentiation between the TMA cores and the full sections is shown in Table 3. The weighted kappa score was 0.65 .

Table 2 Overview of the amount of cores that were evaluable, absent or contained too little tumor in all 108 cases and in the 64 randomly selected cases on the TMA slides

\begin{tabular}{|c|c|c|c|c|c|c|c|}
\hline & $\mathrm{H} \& \mathrm{E}$ & CK5/6 & CK14 & E-cadherin & $\mathrm{Ki}-67$ & p53 & Median \\
\hline \multicolumn{8}{|l|}{ Total TMA cases $(n=108)$} \\
\hline No. of evaluable cores & 293 & 309 & 294 & 306 & 293 & 295 & 295 \\
\hline Percentage & 90 & 95 & 91 & 94 & 90 & 91 & 91 \\
\hline No. of absent cores & 20 & 7 & 22 & 9 & 22 & 22 & 21 \\
\hline Percentage & 6 & 2 & 7 & 3 & 7 & 7 & 6 \\
\hline No. of cores without tumor & 11 & 8 & 8 & 9 & 9 & 7 & 9 \\
\hline Percentage & 4 & 3 & 3 & 3 & 3 & 2 & 3 \\
\hline \multicolumn{8}{|c|}{ Randomly selected TMA cases $(n=64)$} \\
\hline No. of evaluable cores & 176 & 187 & 176 & 185 & 176 & 176 & 176 \\
\hline Percentage & 92 & 97 & 92 & 96 & 92 & 92 & 92 \\
\hline No. of absent cores & 13 & 3 & 13 & 4 & 13 & 13 & 13 \\
\hline Percentage & 7 & 2 & 7 & 2 & 7 & 7 & 7 \\
\hline No. of cores without tumor & 3 & 2 & 3 & 3 & 3 & 3 & 3 \\
\hline Percentage & 2 & 1 & 2 & 2 & 2 & 2 & 2 \\
\hline
\end{tabular}

$H \& E$ : hematoxylin and eosin 
Table 3 Agreement in the degree of differentiation between TMA cores and full sections

\begin{tabular}{rlrrrrr}
\hline \multicolumn{7}{c}{ Full section } \\
& & G1 & G2 & G3 & Total & $\kappa$ \\
\cline { 3 - 7 } & & 2 & 3 & 0 & 5 & \\
TMA & G1 & 2 & 21 & 2 & 25 & \\
& G2 & 0 & 7 & 26 & 33 & \\
& G3 & 0 & 31 & 28 & 63 & 0.65
\end{tabular}

G1: well-differentiated, G2: moderately differentiated, G3: poorly differentiated

Fifty-nine (92\%) of the 64 randomly selected cases stained for CK5/6 were represented by 3 cores (Fig. 1); the 5 remaining cases by 2 cores. The immunohistochemical scores of the TMA and the donor blocks are shown in Table 4. Overall agreement in CK5/6 scores between the TMA and the donor blocks was $98 \%$ with a kappa of 0.93 .

For CK14, two cases were excluded because only one tumor core was left and three cases were also excluded because the two available cores had discrepant immunohistochemical scores. Fifty (85\%) of 59 cases had complete agreement (Table 4). Four cases were scored one class higher on TMA when compared with the full sections. Conversely, five other cases were classified lower on TMA with one case two classes lower. Kappa score was 0.71.

Regarding E-cadherin staining, three assessable cores were present in $89 \%$ of the cases; two cores in $11 \%$. Overall agreement in E-cadherin staining scores was accomplished in $72 \%$ of cases (Table 5 ). In one case, a higher score was found on the TMA compared to the full section. In 17 cases, the expression of E-cadherin was scored lower on TMA than on the full sections. The observed kappa was 0.47 .

Three-core analysis of Ki-67 staining could be performed in $78 \%$ of selected cases and two-core analysis in $19 \%$. Two cases were represented by a single tumor core and were, therefore, excluded from further analysis. Ki-67 staining was scored as "moderate" on both TMA and full sections in $42(69 \%)$ of 61 selected cases. In $79 \%$ of cases, the Ki-67 scores of the TMA were similar to that of the full sections. Thirteen cases were discordant (Table 6); kappa was 0.42 .

With regard to p53 staining, two cores were present in $12(19 \%)$ cases and 3 cores were available in $51(80 \%)$ cases. One case was excluded as it was represented by only one TMA core. Complete agreement was achieved in $87 \%$ of the selected tumors (Table 6). In the eight nonconcordant cases, the difference was one class, resulting in a kappa of 0.86 .

\section{Discussion}

After its introduction in 1998, TMA technology has been applied in the immunohistochemical analysis of various malignancies, including squamous cell carcinomas and adenocarcinomas of the esophagus [3, 5, 18, 19, 25, 41]. Although it seems a very attractive method for highthroughput analysis of hundreds of tissues simultaneously, it may have limitations as the evaluation of the marker
Fig. 1 Example of strong CK5/ 6 staining in TMA cores and the corresponding full section. a Three TMA cores representing one tumor; magnification $\times 20$. b Enlargement of the middle TMA core depicted in a; magnification $\times 100$. $\mathbf{c}$ Part of the slide of the donor block of the same tumor; magnification $\times 100$

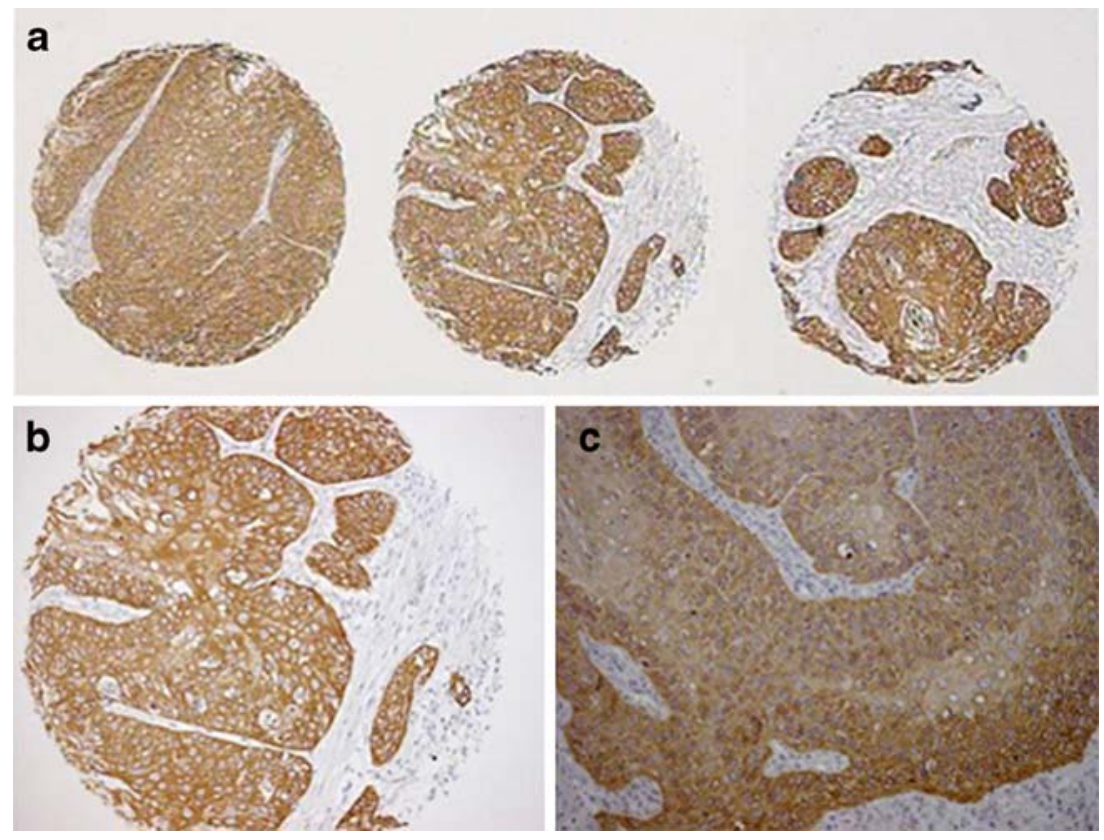


Table 4 Agreement in immunohistochemical scores between TMA cores and full slides stained for CK5/6 and CK14

\begin{tabular}{ccccccc}
\hline \multicolumn{5}{c}{ Full sections } \\
\cline { 3 - 7 } & & $<10 \%$ & $10-80 \%$ & $\geq 80 \%$ & Total & $\kappa$ \\
\hline TMAs & CK5/6 & & & & & \\
& $<10 \%$ & 1 & 1 & 0 & 2 & \\
$10-80 \%$ & 0 & 4 & 0 & 4 & \\
$\geq 80 \%$ & 0 & 0 & 58 & 58 & \\
Total & 1 & 5 & 58 & 64 & 0.93 \\
CK14 & & & & & \\
$<10 \%$ & 5 & 2 & 1 & 8 & \\
$10-80 \%$ & 0 & 11 & 2 & 13 & \\
$\geq 80 \%$ & 0 & 4 & 34 & 38 & \\
Total & 5 & 17 & 37 & 59 & 0.71 \\
\hline
\end{tabular}

expression is reduced from full-section analysis to a few tissue cores of only $0.6 \mathrm{~mm}$ in diameter, especially for proteins that are heterogeneously expressed or that are cell cycle-dependent [36]. It is, therefore, essential to assess in each type of cancer individually and for every molecular marker whether TMA technology is feasible and valid [8, 33]. To our knowledge, this has not been done in esophageal cancer.

In our TMA containing triplicate cores of 108 ESCCs, a median of $9 \%$ of cores was uninformative $(6 \%$ lost during tissue processing and 3\% containing too little tumor), which is comparable to the results reported in other studies $[7,8,27]$. Improper selection of representative tumor areas on the donor block's H\&E slide by the pathologist or incorrect punching of these representative areas out of the donor block can cause tissue cores that contain too little tumor. Possible causes of absent cores are the size and fragility of the tumor tissue used and the aggressiveness of tissue processing applied [31, 35, 42].

Moreover, the number of available cores on the TMA slide depends on the level at which the TMA paraffin block has been sectioned. The slides stained for H\&E, CK14, $\mathrm{Ki}-67$, and p53 were one of the first slides that were cut from our TMA block, whereas sections stained for CK5/6

Table 5 Agreement in immunohistochemical scores between TMA cores and full slides stained for E-cadherin

\begin{tabular}{llrlll}
\hline \multicolumn{5}{c}{ Full sections } \\
& \multirow{2}{*}{ E-cadherin } & $<50 \%$ & $\geq 50 \%$ & Total & $\kappa$ \\
\hline \multirow{2}{*}{ TMA } & $<50 \%$ & 22 & 17 & 39 & \\
& $\geq 50 \%$ & 1 & 24 & 25 & \\
& Total & 23 & 41 & 64 & 0.47 \\
\hline
\end{tabular}

Table 6 Agreement in immunohistochemical scores between TMA cores and full slides stained for Ki-67 and p53

\begin{tabular}{|c|c|c|c|c|c|c|}
\hline & & \multicolumn{5}{|c|}{ Full sections } \\
\hline & & $<10 \%$ & $10-50 \%$ & $\geq 50 \%$ & Total & $\kappa$ \\
\hline \multirow[t]{10}{*}{ TMAs } & $\mathrm{Ki}-67$ & & & & & \\
\hline & $<10 \%$ & 2 & 1 & 0 & 3 & \\
\hline & $10-50 \%$ & 3 & 42 & 3 & 48 & \\
\hline & $\geq 50 \%$ & 0 & 6 & 4 & 10 & \\
\hline & Total & 5 & 49 & 7 & 61 & 0.42 \\
\hline & p53 & & & & & \\
\hline & $<10 \%$ & 19 & 3 & 0 & 22 & \\
\hline & $10-50 \%$ & 0 & 1 & 2 & 3 & \\
\hline & $\geq 50 \%$ & 0 & 3 & 35 & 38 & \\
\hline & Total & 19 & 7 & 37 & 63 & 0.86 \\
\hline
\end{tabular}

and E-cadherin were taken slightly deeper. On these latter sections, a lower number of absent cores was observed (Table 2), showing that not all cores were placed at the exact same level in the TMA block during TMA construction, mainly due to dissimilar thicknesses of the donor paraffin blocks that were used to construct the TMA [34].

The agreement in immunohistochemical results of the markers between our TMA and the full sections varied from moderate to almost perfect $(\kappa=0.42$ to 0.93$)$, which is consistent with the results reported in other TMA validation studies $[4,7,8,31,35]$. The observed variation in agreement could be due to tumor heterogeneity, topographical variation in the expression pattern of the molecular marker, or to the scoring criteria used [31].

Regarding tumor heterogeneity, the optimal amount of tissue cores incorporated in the TMA has been a matter of debate. Several validation studies have shown that three cores are highly representative for the full section $[6,11$, $12,28]$. The addition of a fourth core did not add to the percentage of agreement in a colorectal cancer TMA [12]. Moreover, the more cores punched per case, the fewer cases can be placed into the TMA reducing throughput. Adding a fourth core may nevertheless be worthwhile in tissues prone to uninformative cores due to small lesions such as dysplasias or carcinomas in situ [42]. In our TMA, the amount of uninformative cores was low (5-10\%), probably because ESCCs have a large diameter, thereby increasing the chance of obtaining a core containing tumor tissue. Taken together, we consider it justified to utilize three biopsy cores in ESCCs. Nonetheless, using such a low amount of cores requires careful selection of the tumor regions by an experienced pathologist to deal with the heterogeneity of the tumor in the TMA [33].

The agreement between TMA and full sections was substantial to almost perfect for CK5/6 and CK14. Because $91 \%$ of cases have shown a very strong expression of CK5/ 
Fig. 2 Representative example of E-cadherin staining in TMA cores and the corresponding full section. a Three TMA cores representing one tumor; magnification $\times 20$. b Enlargement of the right TMA core depicted in a) magnification $\times 100$. c Part of the slide of the donor block of the same tumor; magnification $\times 100$
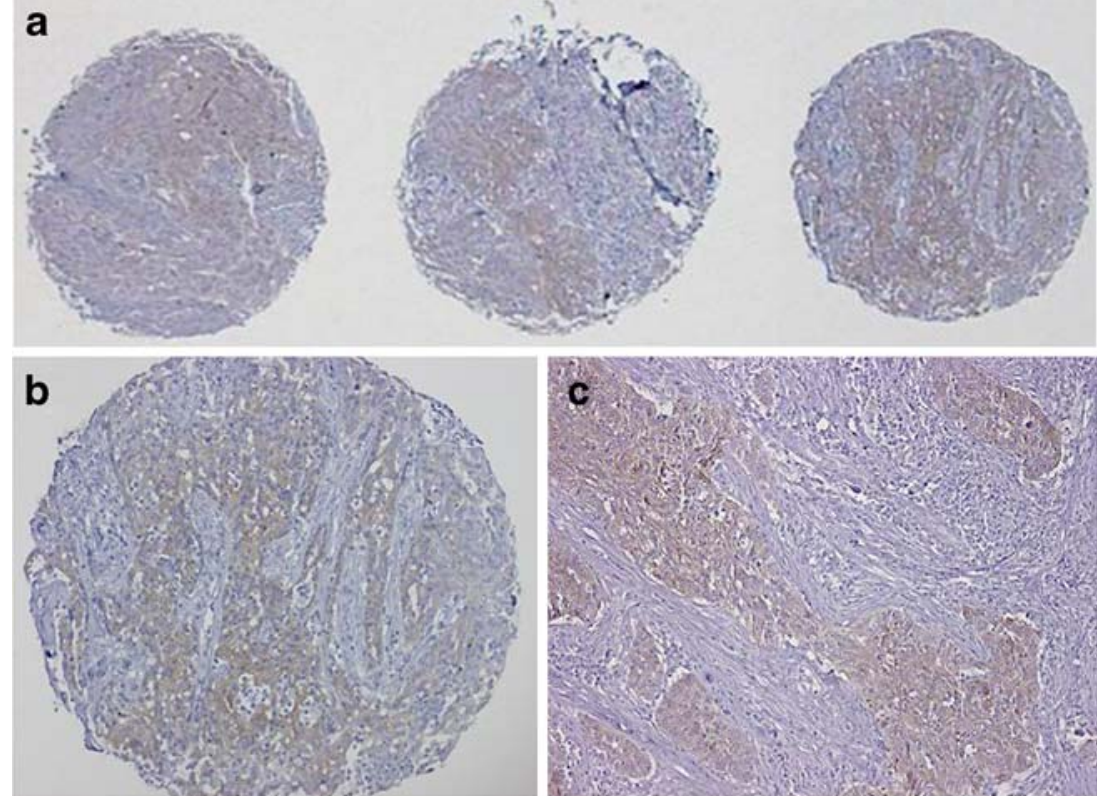

6 and only 1 of 64 cases showed negative staining, this molecular marker does not subdivide ESCCs and consequently will not be a prognostic marker for this malignancy. CK14 was more evenly distributed over the three scoring groups, but because one case was scored two classes lower on TMA when compared to the full section, kappa was lower when compared to $\mathrm{CK} 5 / 6$.

The relatively moderate concordance in case of Ki-67 may be explained by the fact that almost $80 \%$ of cases were situated in one category (staining of $10-50 \%$ of tumor cells) with 13 discordant cases deviating from this category. Ecadherin also had a moderate concordance, mainly because the relatively faint staining intensity of this molecular maker made its assessment in our TMA very difficult (Fig. 2).

TMA technology was also found to be valid for determining the histologic grade of differentiation in ESCC. Complete agreement between TMA and full sections occurred in $78 \%$ (49 out of $63 ; \kappa=0.65$ ) of selected cases, which is high when compared to the $40 \%$ agreement achieved in a TMA of bladder cancer [22]. Due to its homogeneous staining pattern, p53 showed excellent concordance $(\kappa=0.86)$ in our microarray (Fig. 3).

The concurrence between the TMA and the full sections is affected by the cut-off values of the immunohistochemical scoring system of the stainings as well $[7,31]$. The
Fig. 3 Representative example of p53 staining in TMA cores and the corresponding full section. a Three TMA cores representing one tumor; magnification $\times 20$. $\mathbf{b}$ Enlargement of the left TMA core depicted in $\mathbf{a}$; magnification $\times 100$. $\mathbf{c}$ Part of the slide of the donor block of the same tumor; magnification $\times 100$
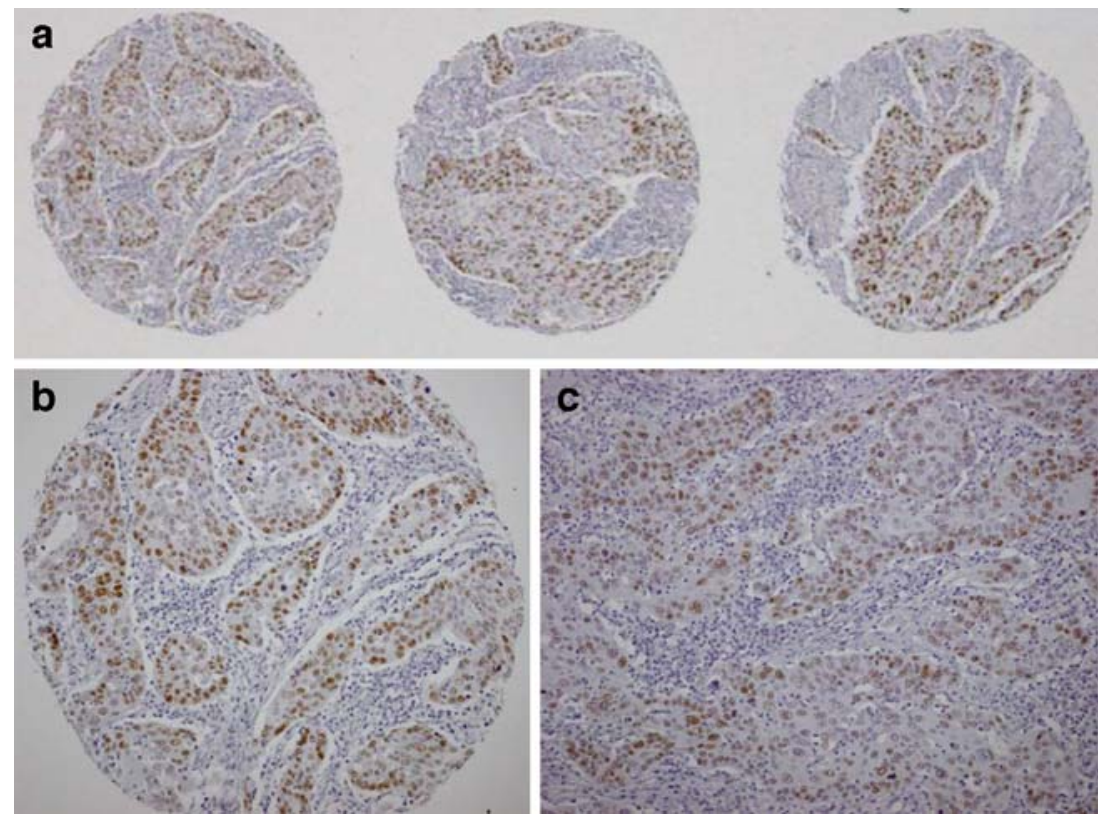
application of a two-class scoring system in an endometrial cancer TMA improved $\kappa$ to 1.0 compared to 0.81 with a three-class system [7]. In our study, the two-class scoring system did not substantially affect the kappa (data not shown). Because the E-cadherin expression had a very low intensity in our ESCCs, we have chosen to apply a two-class system. In addition, the cut-off values indicating a strong immunohistochemical expression were set higher in the cytokeratins $(80 \%)$ than in the other molecular markers (cut-off value 50\%) because otherwise practically all tumors would be designated having a strong expression of cytokeratins.

Now that our esophageal cancer TMA has been validated, it will be used to correlate the expression of various molecular pathways with clinicopathologic data, aiming at detecting markers of prognostic significance and molecular targets for new therapies. Because the agreement between TMA slides and full sections depended on the molecular marker stained for, it should be considered to assess the expression pattern of a marker on a full section first, before staining a TMA slide. When a focal or heterogeneous expression pattern is noticed, it might be more valuable to assess marker expression by means of full sections instead of TMA. On the other hand, when a marker shows a homogeneously diffuse expression pattern, staining a TMA slide does allow for high-throughput screening of tumors. When a prognostic molecular marker has been identified by means of TMA technology, it is recommended to verify the results by full-section analysis.

In conclusion, this study has demonstrated TMA technology to be a valid method for immunohistochemical analysis in ESCC with agreement levels for well-known molecular markers with different staining potential between TMA and full sections ranging from moderate to almost perfect.

Conflict of interest statement We declare that we have no conflict of interest.

Open Access This article is distributed under the terms of the Creative Commons Attribution Noncommercial License which permits any noncommercial use, distribution, and reproduction in any medium, provided the original author(s) and source are credited.

\section{References}

1. Alexiou C, Khan OA, Black E, Field ML, Onyeaka P, Beggs L, Duffy JP, Beggs DF (2006) Survival after esophageal resection for carcinoma: the importance of the histologic cell type. Ann Thorac Surg 82:1073-1077

2. Camp RL, Charette LA, Rimm DL (2000) Validation of tissue microarray technology in breast carcinoma. Lab Invest 80:19431949
3. Chen AG, Yu ZC, Yu XF, Cao WF, Ding F, Liu ZH (2006) Overexpression of Ets-like protein 1 in human esophageal squamous cell carcinoma. World J Gastroenterol 12:7859-7863

4. Chen B, van den Brekel MW, Buschers W, Balm AJ, van Velthuysen ML (2003) Validation of tissue array technology in head and neck squamous cell carcinoma. Head Neck 25:922930

5. Cheng MF, Tzao C, Tsai WC, Lee WH, Chen A, Chiang H, Sheu LF, Jin JS (2006) Expression of EMMPRIN and matriptase in esophageal squamous cell carcinoma: correlation with clinicopathological parameters. Dis Esophagus 19:482-486

6. Fernebro E, Dictor M, Bendahl PO, Ferno M, Nilbert M (2002) Evaluation of the tissue microarray technique for immunohistochemical analysis in rectal cancer. Arch Pathol Lab Med 126:702705

7. Fons G, Hasibuan SM, Velden JV, Kate FJ (2007) Validation of tissue micro array technology in endometrioid cancer of the endometrium. J Clin Pathol 60:500-503

8. Gomaa W, Ke Y, Fujii H, Helliwell T (2005) Tissue microarray of head and neck squamous carcinoma: validation of the methodology for the study of cutaneous fatty acid-binding protein, vascular endothelial growth factor, involucrin and Ki-67. Virchows Arch 447:701-709

9. Griffin MC, Robinson RA, Trask DK (2003) Validation of tissue microarrays using p53 immunohistochemical studies of squamous cell carcinoma of the larynx. Mod Pathol 16:1181-1188

10. Han U, Can OI, Han S, Kayhan B, Onal BU (2007) Expressions of p53, VEGF C, p21: could they be used in preoperative evaluation of lymph node metastasis of esophageal squamous cell carcinoma? Dis Esophagus 20:379-385

11. Hoos A, Urist MJ, Stojadinovic A, Mastorides S, Dudas ME, Leung DH, Kuo D, Brennan MF, Lewis JJ, Cordon-Cardo C (2001) Validation of tissue microarrays for immunohistochemical profiling of cancer specimens using the example of human fibroblastic tumors. Am J Pathol 158:1245-1251

12. Jourdan F, Sebbagh N, Comperat E, Mourra N, Flahault A, Olschwang S, Duval A, Hamelin R, Flejou JF (2003) Tissue microarray technology: validation in colorectal carcinoma and analysis of p53, hMLH1, and hMSH2 immunohistochemical expression. Virchows Arch 443:115-121

13. Kamangar F, Dores GM, Anderson WF (2006) Patterns of cancer incidence, mortality, and prevalence across five continents: defining priorities to reduce cancer disparities in different geographic regions of the world. J Clin Oncol 24:2137-2150

14. Kononen J, Bubendorf L, Kallioniemi A, Barlund M, Schraml P, Leighton S, Torhorst J, Mihatsch MJ, Sauter G, Kallioniemi OP (1998) Tissue microarrays for high-throughput molecular profiling of tumor specimens. Nat Med 4:844-847

15. Kundel HL, Polansky M (2003) Measurement of observer agreement. Radiology 228:303-308

16. Lagarde SM, Ten Kate FJ, de Boer DJ, Busch OR, Obertop H, van Lanschot JJ (2006) Extracapsular lymph node involvement in node-positive patients with adenocarcinoma of the distal esophagus or gastroesophageal junction. Am J Surg Pathol 30:171176

17. Landis JR, Koch GG (1977) The measurement of observer agreement for categorical data. Biometrics 33:159-174

18. Langer R, Von Rahden BH, Nahrig J, Von Weyhern C, Reiter R, Feith M, Stein HJ, Siewert JR, Hofler H, Sarbia M (2006) Prognostic significance of expression patterns of c-erbB-2, p53, p16INK4A, p27KIP1, cyclin D1 and epidermal growth factor receptor in oesophageal adenocarcinoma: a tissue microarray study. J Clin Pathol 59:631-634

19. Liu W, Yu ZC, Cao WF, Ding F, Liu ZH (2006) Functional studies of a novel oncogene TGM3 in human esophageal squamous cell carcinoma. World J Gastroenterol 12:3929-3932 
20. Mariette C, Piessen G, Triboulet JP (2007) Therapeutic strategies in oesophageal carcinoma: role of surgery and other modalities. Lancet Oncol 8:545-553

21. Nair KS, Naidoo R, Chetty R (2005) Expression of cell adhesion molecules in oesophageal carcinoma and its prognostic value. $\mathrm{J}$ Clin Pathol 58:343-351

22. Nocito A, Bubendorf L, Tinner EM, Suess K, Wagner U, Forster T, Kononen J, Fijan A, Bruderer J, Schmid U, Ackermann D, Maurer R, Alund G, Knonagel H, Rist M, Anabitarte M, Hering F, Hardmeier T, Schoenenberger AJ, Flury R, Jager P, Fehr JL, Schraml P, Moch H, Mihatsch MJ, Gasser T, Sauter G (2001) Microarrays of bladder cancer tissue are highly representative of proliferation index and histological grade. J Pathol 194:349-357

23. Pacifico MD, Grover R, Richman P, Daley F, Wilson GD (2004) Validation of tissue microarray for the immunohistochemical profiling of melanoma. Melanoma Res 14:39-42

24. Pedrazzani C, deManzoni G, Marrelli D, Giacopuzzi S, Corso G, Bernini M, Roviello F (2007) Nodal staging in adenocarcinoma of the gastro-esophageal junction. Proposal of a specific staging system. Ann Surg Oncol 14:299-305

25. Reichelt U, Duesedau P, Tsourlakis MC, Quaas A, Link BC, Schurr PG, Kaifi JT, Gros SJ, Yekebas EF, Marx A, Simon R, Izbicki JR, Sauter G (2007) Frequent homogeneous HER-2 amplification in primary and metastatic adenocarcinoma of the esophagus. Mod Pathol 20:120-129

26. Rizk N, Venkatraman E, Park B, Flores R, Bains MS, Rusch V (2006) The prognostic importance of the number of involved lymph nodes in esophageal cancer: implications for revisions of the American Joint Committee on Cancer staging system. J Thorac Cardiovasc Surg 132:1374-1381

27. Rosen DG, Huang X, Deavers MT, Malpica A, Silva EG, Liu J (2004) Validation of tissue microarray technology in ovarian carcinoma. Mod Pathol 17:790-797

28. Rubin MA, Dunn R, Strawderman M, Pienta KJ (2002) Tissue microarray sampling strategy for prostate cancer biomarker analysis. Am J Surg Pathol 26:312-319

29. Sato F, Shimada Y, Watanabe G, Uchida S, Makino T, Imamura M (1999) Expression of vascular endothelial growth factor, matrix metalloproteinase-9 and E-cadherin in the process of lymph node metastasis in oesophageal cancer. Br J Cancer 80:1366-1372

30. Shiozaki H, Doki Y, Yamana H, Isono K (2002) A multiinstitutional study of immunohistochemical investigation for the roles of cyclin D1 and E-cadherin in superficial squamous cell carcinoma of the esophagus. J Surg Oncol 79:166-173

31. Su Y, Shrubsole MJ, Ness RM, Cai Q, Kataoka N, Washington K, Zheng W (2006) Immunohistochemical expressions of Ki-67, cyclin D1, beta-catenin, cyclooxygenase-2, and epidermal growth factor receptor in human colorectal adenoma: a validation study of tissue microarrays. Cancer Epidemiol Biomarkers Prev 15:1719 1726

32. Takeno S, Noguchi T, Takahashi Y, Fumoto S, Shibata T, Kawahara K (2007) Assessment of clinical outcome in patients with esophageal squamous cell carcinoma using TNM classification score and molecular biological classification. Ann Surg Oncol 14:1431-1438

33. Tawfik El-Mansi M, Williams AR (2006) Validation of tissue microarray technology using cervical adenocarcinoma and its precursors as a model system. Int J Gynecol Cancer 16:1225-1233

34. Tzankov A, Went P, Zimpfer A, Dirnhofer S (2005) Tissue microarray technology: principles, pitfalls and perspectives - lessons learned from hematological malignancies. Exp Gerontol 40:737-744

35. Van den Eynden GG, Van dA I, Van Laere S, Colpaert CG, van Dam P, Merajver S, Kleer CG, Harris AL, Van Marck EA, Dirix LY, Vermeulen PB (2004) Validation of a tissue microarray to study differential protein expression in inflammatory and noninflammatory breast cancer. Breast Cancer Res Treat 85:13-22

36. van Diest PJ, Vleugel M, van der Groep P, van der Wall E (2005) VEGF-D and HIF-1alpha in breast cancer. J Clin Pathol 58:335

37. Wittekind C, Greene FL, Hutter RVP, Klimpfinger M, Sobin LH (ed) (2004) TNM Atlas. Illustrated guide to the TNM/pTNM classification of malignant tumors. Springer, Berlin

38. Xu F, Zhong W, Li J, Shanshen Z, Cui J, Nesland JM, Suo Z (2005) Predictive value of EphA2 and EphrinA-1 expression in oesophageal squamous cell carcinoma. Anticancer Res 25:2943-2950

39. Xu FP, Xie D, Wen JM, Wu HX, Liu YD, Bi J, Lv ZL, Zeng YX, Guan XY (2007) SRC-3/AIB1 protein and gene amplification levels in human esophageal squamous cell carcinomas. Cancer Lett 245:69-74

40. Xu M, Jin YL, Fu J, Huang H, Chen SZ, Qu P, Tian HM, Liu ZY, Zhang W (2002) The abnormal expression of retinoic acid receptor-beta, p53 and Ki67 protein in normal, premalignant and malignant esophageal tissues. World J Gastroenterol 8:200-202

41. Xue LY, Hu N, Song YM, Zou SM, Shou JZ, Qian LX, Ren LQ, Lin DM, Tong T, He ZG, Zhan QM, Taylor PR, Lu N (2006) Tissue microarray analysis reveals a tight correlation between protein expression pattern and progression of esophageal squamous cell carcinoma. BMC Cancer 6:296

42. Yang XR, Charette LA, Garcia-Closas M, Lissowska J, Paal E, Sidawy M, Hewitt SM, Rimm DL, Sherman ME (2006) Construction and validation of tissue microarrays of ductal carcinoma in situ and terminal duct lobular units associated with invasive breast carcinoma. Diagn Mol Pathol 15:157-161 